\title{
Risk Factors of Orthopaedic Implant Associated Infection
}

\author{
Authors \\ Dr Kiran A M ${ }^{1}$, Dr Muhammed Sageer $A^{2^{*}}$, Dr Sabarisree $\mathbf{M}^{3}$ \\ ${ }^{1}$ Senior resident, Department of Orthopaedics, Govt. Medical College, Thiruvananthapuram \\ ${ }^{2}$ Additional Professor in Orthopaedics, Govt Medical College, Thiruvananthapuram \\ ${ }^{3}$ Additional Professor in Orthopaedics, Govt Medical College, Thiruvananthapuram \\ *Corresponding Author \\ Dr Muhammed Sageer A
}

Additional Professor in Orthopaedics, Govt Medical College, Thiruvananthapuram, India

\begin{abstract}
Objective: To study the risk factors of implant associated infection among patients admitted in orthopaedic wards in government medical college Thiruvananthapuram.

Materials and Methods: This is a case-control study which was carried out from march 2017 to March 2018 in government medical college. Thiruvanathapuram. In this study period 67 cases of implant associated infection and 134 controls were taken.

Results: variables were studied for any significant association with risk implant associated infection. We found diabetes mellitus (chi square value of 16.42 and p value 0.001), smoking (chi square value:4.847 and p value:0.028), open fracture (chi square value: 4.065 and p value 0.044), preop haemoglobin level (chi square value:6.869 and $p$ value 0.009), duration between trauma and first dose antibiotics (chi square value:4.38 and $p$ value:0.036), external fixation (chi square value: 4.809 and $p$ value: 0.028) had a significant association with risk of implant associated infection. Elevated ESR level had a significant association with bad outcome on follow up.
\end{abstract}

Keywords: Implant Associated, Infection.

\section{Introduction}

Surgical site infections are one of the most common nosocomial infections besides pneumonia, urinary tract infections. Deep Surgical Site Infections (SSI) following orthopedic implant surgery result in the drainage of community and hospital resources. So every possible measure should be taken to reduce potential risk factors associated with deep SSI.

The development of SSI is very complex. It depends on several different interacting properties and prerequisites related to the patient, the surgical environment and finally the surgical technique. Open fractures are associated with complications that can result in increased length of hospital stays, multiple operative interventions and even amputation. One of the factors that influence the extent of these complications is exposure and contamination of the open fracture with environmental microorganisms. C-reactive protein (CRP), and erythrocyte sedimentation rate (ESR) are used for the assessment of severity of infections. 
Most implant associated infections occur in first week of surgery. Sometimes an infection may develop long after fracture fixation and healing, as a result of hematogenous spread. This should be suspected in those with a compromised immunity. Compared to non infected orthopedic patients, orthopedic patients with Surgical Site Infection (SSI) stay 2 weeks longer, have double the rate of rehospitalization, and generated $300 \%$ greater health-care costs.

\section{Aim}

To study the risk factors of implant associated infection among patients admitted in orthopaedic wards in government medical college Thiruvananthapuram

\section{Materials and Methods}

Study Design: Case-control study.

Study Setting: Orthopaedic wards of government medical college Trivandrum.

Study Period: 1 year from March 2017 to March 2018.

Study Population: Case- patients admitted with orthopaedic implant associated infection

Control- Patients who are treated with orthopaedic implants and shows no clinical evidence of infection after a period of 3 months.

Sample Size: Case-Minimum of 67 Cases. Control -134

\section{Inclusion Criteria}

All consecutive cases of orthopaedic implant associated infection admitted in orthopaedic wards of Government Medical College Thiruvananthapuram during study period will be included in my study.

\section{Exclusion Criteria}

Patients not giving consent.

\section{Methodology}

Cases and controls are selected according to the inclusion and exclusion criteria. They are explained about the research and consent will be obtained. They will be given a proforma listing personal details to be filled by themselves.

\section{Statistical Analysis}

Qualitative data will be expressed in percentage and proportions quantitative data will be expressed in mean and standard deviation.

\section{Data Collection}

Data collection is by question are method.

\section{Ethical Considerations}

Research work will be started only after getting clearance from college authority and ethical committee. Confidentiality will be maintained in all stages of the study.

\section{Budget and Funding}

No financial burden occurs for study subjects. All expenses will be met by principle investigator

\section{Results}

- Age group in this study range from 12 to 95 years. Mean age found was 54 years for cases and 49 years for controls. Association of age with risk of implant associated infection was found not to be significant with $\mathrm{p}$ value 0.11

- In case group 63\% were males and $37 \%$ were females. In control group $69 \%$ were males and $31 \%$ were females. Association of sex with risk of implant associated infection was found not to be significant with $\mathrm{p}$ value 0.397

- 32 out of 67 cases that is $48 \%$ had Diabetes Mellitus while 27 out of 134 controls that is 20\% had Diabetes Mellitus. Association of diabetes mellitus with risk of implant associated infection was found to be significant with $\mathrm{p}$ value 0.001 (fig1).

- 19 out of 67 cases that is $28 \%$ and 25 out of 134 controls that is $19 \%$ had obesity. Association of obesity with risk of implant associated infection was found not to be significant with $\mathrm{p}$ value 0.117 (fig:2) 
- Out of 67 cases 35 patients had habit of smoking and out of 134 controls 29 had smoking. Association of smoking with risk of implant associated infection was found to be significant with p value0.028(fig:3)

- Out of 67 cases 29 were done elective and 38 were done emergency. Out of 134 controls 68 were done elective and 66 done emergency. Association of type of surgery with risk of implant associated infection was found not to be significant with $\mathrm{p}$ value 0.318(fig:4)

- Out of 134 cases 64 were closed and 70 were open. Association of type of fracture with risk of implant associated infection was found to be significant with $\mathrm{p}$ value 0.044 .

- 47 cases and 68 controls had haemoglobin level below 11. Association of haemoglobin level with risk of implant associated infection was found to be significant with $p$ value 0.009.(fig:5)

- Association of ESR with risk bad prognosis of implant associated infection was found to be significant with $\mathrm{p}$ value 0.001 (fig: 6 ).

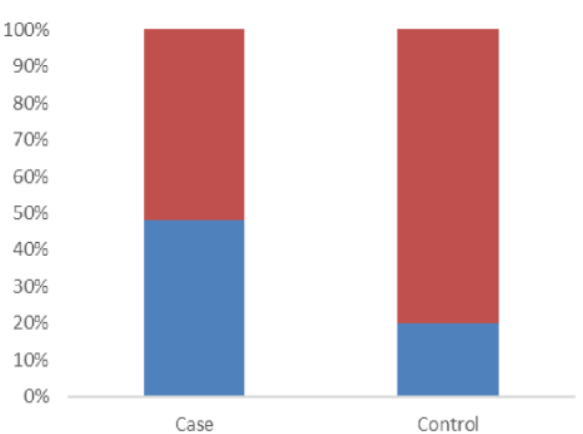

DM

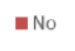

- Yes

Fig: 1

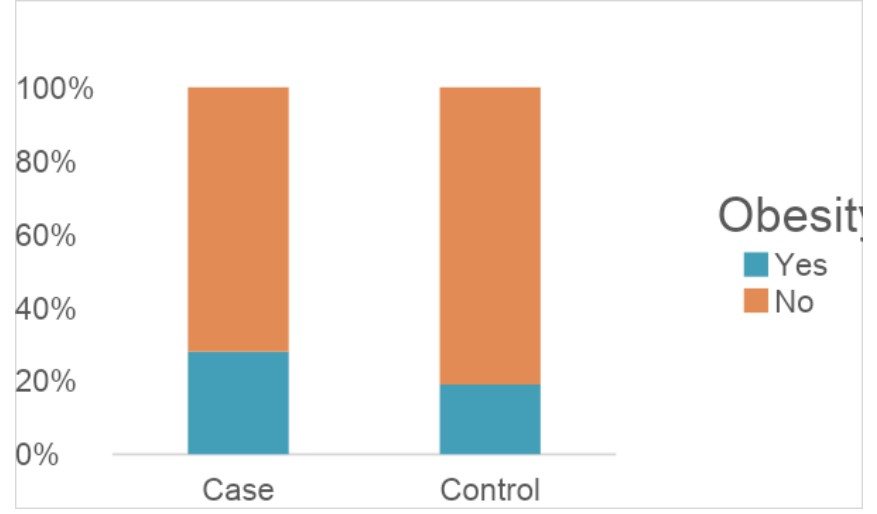

Fig: 2

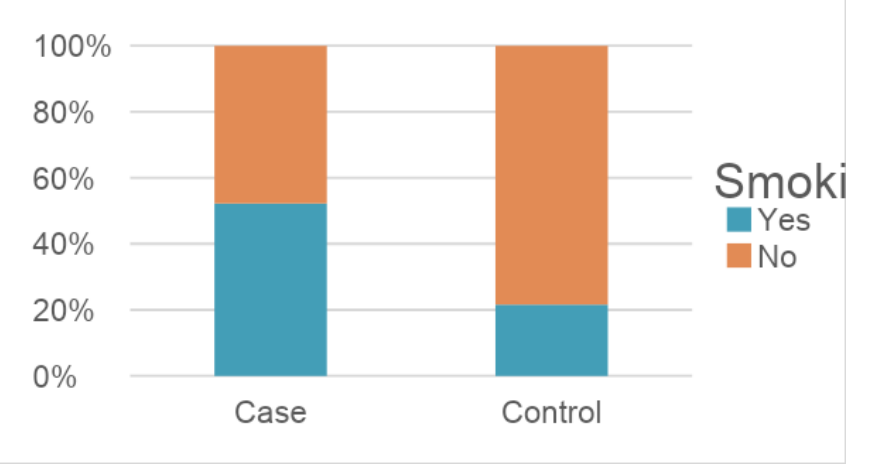

Fig: 3

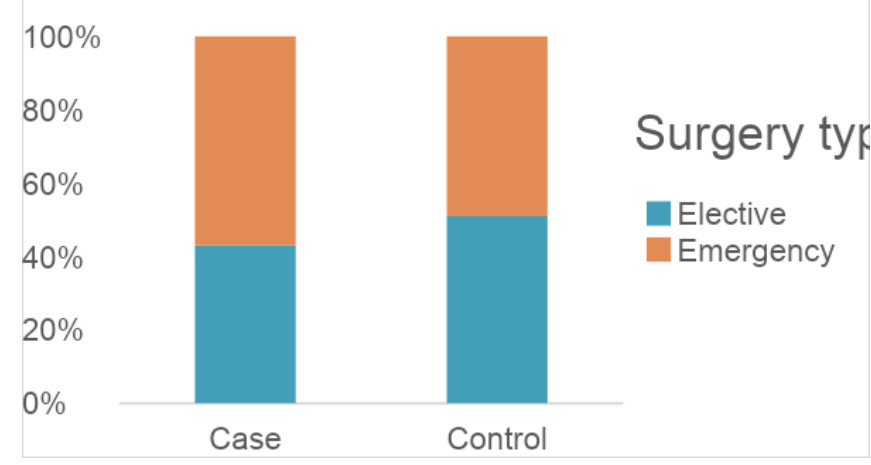

Fig: 4

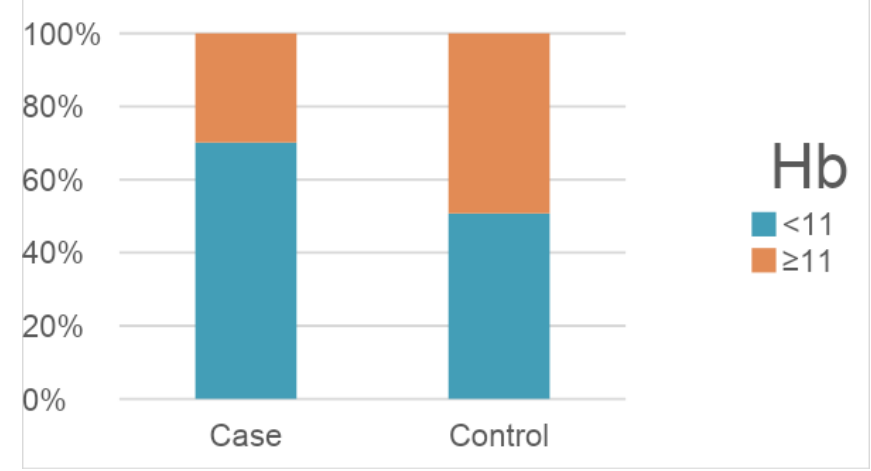

Fig: 5

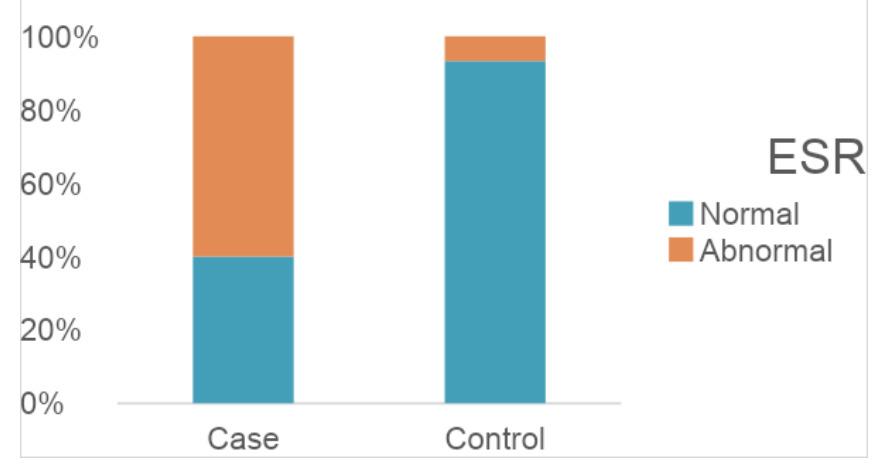

Fig: 6 


\section{Discussion}

In our study mean age of case is found to be 54 years and controls to be 49 years. There was no significant association between age and risk of implant associated infection. Similar studies conducted by Mohamed Al-Mayahi et $\mathrm{al}^{1}$ and Muhammad Thahir et $\mathrm{al}^{2}$ found that there was no relation between age and risk of implant associated infection. Study conducted by Dr. Amaradeep $\mathrm{G}$ et $\mathrm{al}^{3}$ found that there was increased risk in old age.

There was no significant gender associated risk found in our study. Study conducted by Mohamed Al-Mayahi et $\mathrm{al}^{1}$ demonstrated similar results. Stephen Apanga et $\mathrm{al}^{4}$ done a similar study in Ghana and found increased risk in males.

Discharge from wound was in 63 out of 67 patients. 4 cases had infection without remarkable discharge. $70 \%$ of cases had fever while $30 \%$ had no history of fever.

32 (48\%) cases and 27 controls (20\%) had diabetes mellitus. Prevalence of diabetes in controls is found to be comparable with the current diabetic status of Kerala. We found a significant relation between diabetes mellitus and risk of implant associated infection (chi square value of 16.42 and $p$ value 0.001 ). Similar studies were done by Berkes $\mathrm{M}$ et $\mathrm{al}^{5}$ and Dronge $\mathrm{A}$ et $\mathrm{al}^{6}$ found increased risk of infection in diabetic patients. Boris Mraovic et $\mathrm{al}^{7}$ also got similar findings regarding diabetes and periprosthetic infection. Zmistowski et al concluded that perioperative hyperglycemia after total joint arthroplasty is a risk factor for infection.

3 cases had active tuberculosis and one of the controls had TB. Few studies were done in this topic. We were not able to demonstrate any significant risk. The reason may be less number of cases.

19 cases (28\%) and 25 controls (19\%) had obesity. No significant relation is demonstrated between obesity and risk of implant associated infection. Similar studies were done by Michelle M. Dowsey ${ }^{8}$ and Malinzak RA $^{9}$ and found that there were no increased risk of implant associated infection with obesity but morbid obesity (BMI>40) increase the risk of implant associated infection. In our study samples had only obesity and none had morbid obesity.

In our study only 2 cases and 1 control were immunocompromised. The result is that there is no significant relation between immunocompromised condition and risk of implant associated infection. Study done by James W. M. Kigera et $\mathrm{al}^{10}$ on HIV infection and implant associated infection demonstrated a significant relation. In our study the smaller sample size of immunocompromised patients may the reason for different result.

In our study smoking found to have a significant association with risk of implant associated infection (chi square value 4.847 and $p$ value 0.028). Studies done by Lindstrom ${ }^{11}$ on the same topic demonstrated significant relation between smoking and implant associated infection.

Compound fractures have more risk of infection than closed fracures (chi square 4.065 and $\mathrm{p}$ value of 0.044). The results are comparable with that of Gustilo-Anderson et al who was the pioneer in this aspect. ${ }^{12}$ We also observed that as we move down Gustilo and Anderson type the chance of infection also increased.

We observed a significant relation between low preop haemoglobin level and risk of implant associated infection (chi square value 6.869 and $p$ value of 0.009). The results are comparable with that of previous studies done by Michelle $\mathrm{M}$. Dowsey $^{13}$

We found a significant relation of duration from trauma to first dose antibiotic with risk of implant associated infection (chi square value $4.38 \mathrm{p}$ value 0.036). The sample contained both closed and open fractures.

Fractures reduced with external fixative devices are significantly more infected than internal implants (chi square value 4.809 and $p$ value 0.028). This shows a type of spurious relationship because badly compound fractures are stabilized by external fixations than less compound one. Obviously more compound fractures have more 
chance of infection. This fact was given earlier in the discussion as well as by study done by Gustilo and Anderson ${ }^{12}$.

In our study elevated initial ESR level had significant relation with bad outcome of infection on follow up. (chi square value 42.844 and $p$ value 0.001).

\section{Conclusion}

- In the present study of risk factors of implant associated infection we have studied 24 variables for any significant association with risk of implant associated infection.

- We found diabetes mellitus, smoking, open fracture, and low preop haemoglobin level and longer duration of trauma to first dose antibiotics had a significant association.

- Pre op control of glycemic levels, strict smoking cessation and correction of anaemia before elective surgery may help to reduce implant associated infection.

- Elevated initial ESR is associated with bad outcome of implant associated infection.

- Future studies are recommented for validation of the observed risk factors.

\section{Reference}

1. Mohamed Al-Mayahi et al Remission rate of implant-related infections following revision surgery after fractures. Int Orthopaedics. 2013 Nov; 37(11): 2253-2258.

2. Muhammad Thahir et al. International Journal of Research in Orthopaedics JanuaryFebruary 2018 Vol 4 Issue 1.

3. Rao NB et al. A Prospective Study on the Postoperative Wound Infections Journal of Clinical and Diagnostic Research. 2012 :6(7):1266-71.

4. Stephen Apanga, Jerome Adda, Mustapha Issahaku, Jacob Amofa, Kuewu Rita Ama, Mawufemor. Post Operative Surgical Site Infection in a Surgical Ward of a Tertiary Care Hospital in Northern Ghana. International Journal of Health Science. 2014; 2(1):207-12.
5. Berkes M, Obremskey WT, Scannell B. Maintenance of hardware after early postoperative infection following fracture internal fixation. $\mathrm{J}$ Bone Joint Surg. 2010;92:823-828.

6. Dronge AS, Perkal MF, Kancir S. Long-term glycemic control and postoperative infectious complications. Arch Surg. 2006 Apr;141(4): 375-380.

7. Mraovic B,Suh D, Jacovides C,. Perioperative hyperglycemia and postoperative infection after lower limb arthroplasty. Journal Diabetes Science Technology 2011;5:412-8.

8. Dowsey MM, Choong PF. Obese diabetic patients are at substantial risk or deep in ection a ter primary TKA. Clin Orthop Relat Res. 2009 Jun;467(6):1577-1581.

9. Malinzak RA, Ritter MA, Berend ME. Morbidly obese, diabetic, younger, and unilateral joint arthroplasty patients have elevated total joint arthroplasty infection rates. Joint Arthroplasty. 2009 Sep;24.

10. James W. M. Kigera et al. Is There an Increased Risk of Post-Operative Surgical Site Infection after Orthopaedic Surgery in HIV Patients? A Systematic Review and Meta-Analysis. Journal of Bone Joint Surgery June 2005 477-479.

11. Lindstrom D et al. Effects of a perioperative smoking cessation intervention on postoperative complications: a randomized trial. Ann Surg. 2008;248:739-745.

12. Gustilo RB, Anderson JT. Prevention of infection in the treatment of one thousand and twenty-five open fractures of long bones: retrospective and prospective analyses. J Bone Joint Surgery Am.1976 Jun;58(4):453458.

13. Dowsey MM, Choong PF. Obese diabetic patients are at substantial risk or deep in ection a ter primary TKA. Clin Orthop Relat Res. 2009 Jun;467(6):1577-1581. 